\title{
$\mathcal{A}$ HERITAGH lournal of Social Studies
}

OJS: http://heritage.iain-jember.ac.id

\section{Penanaman Nilai Kearifan Lokal pada Peserta Didik Melalui Pendidikan Multikultular}

\section{Integration of Local Wisdom Values to Students Through Multikultular Education}

\author{
1Irman Syarif, 2Muhidin Abuamar Ratuloly \\ 1 Universitas Muhammadiyah Enrekang, 2Universitas Muhammadiyah Kupang \\ (e-mail: 1irmanstkip@gmail.com 2muhidinabuamarratuloly@gmail.com)
}

\begin{abstract}
This study aims to find out the value of local wisdom in students and what factors influence the difference in local wisdom based on multikultular in elementary school. This research method is a qualitative description, data collection techniques are observation, interview and documentation. Data analysis starts from data collection, data reduction, withdrawal of conclusions. The results showed that local wisdom is embedded in elementary school students through formal and nonformal learning, formal learning includes daily teaching activities from 07:30-13:00 while nonformal learning includes extracurricular activities in the form of olaraga practice, dance, music and habituation of living together in the school environment. Fostering local wisdom in elementary school through learning activities teaching the learning process emphasizes on optimizing the role of rationality for students, practice and habituation of dissent. The factors that influence multicultural-based local wisdom differences in elementary schools are the diversity of students who have a wide range of religious differences, social status, gender, ability, age and race, and the collaboration of students in participating in sports and arts events.
\end{abstract}

\begin{abstract}
Abstrak
Penelitian ini bertujuan mengetahui nilai kearifan lokal pada peserta didik dan faktor apa saja mempengaruhi perbedaan kearifan lokal berbasis multikultular di Sekolah Dasar. Metode penelitian ini adalah deskripsi kualitatif, teknik pengumpulan data adalah observasi, wawancara dan dokumentasi. Analisis data dimulai dari pengumpulan data, reduksi data, penarikan kesimpulan. Hasil penelitian menunjukkan bahwa kearifan lokal yang tertanam pada peserta didik Sekolah Dasar melalui pembelajaran formal dan nonformal, pembelajaran formal meliputi kegiatan belajar mengajar setiap hari dari jam 07:30-13:00 sedangkan pembelajaran nonformal meliputi ekstrakurikuler berupa latihan olaraga, tarian, musik dan pembiasaan hidup bersama di lingkungan sekolah. Penumbuhkan kearifan lokal di Sekolah Dasar dilakukan melalui proses pembelajaran yang menekankan pada optimalisasi peran rasionalitas bagi siswa, praktek dan pembiasaan perbedaan pendapat. Fakor-faktor yang mempengaruhi perbedaan kearifan lokal berbasis multikultural di Sekolah Dasar adalah keberagaman siswa karena memiliki berbagai macam perbedaan, yaitu, perbedaan agama, status sosial, dan ras, serta pengelaborasian peserta didik dalam mengikuti lomba olahraga dan seni.
\end{abstract}

\section{Kata kunci: kearifan lokal, pendidikan multikultural}




\section{Pendahuluan}

Kearifan lokal peserta didik di SDN 98 Tongko adalah bersifat bijaksana, penuh toleransi, penanaman nilai-nilai baik yang diadopsi dari masyarakatnya. Untuk mengetahui kearifan lokal di SDN 98 Tongko, kita harus bisa memahami nilai-nilai budaya yang baik yang ada di dalam sekolah tersebut. Nilai-nilai kearifan lokal ini sebenarnya sudah diajarkan secara turun temurun oleh orang tua kepada anak-anaknya (Syahrul, Arifin, Datuk, Almu, \& Ramlah, 2019). Budaya Gotong Royong, saling menghormati dan Tepa Salira merupakan contoh kecil dari kearifan lokal (Kennedy, Tobing, Lumbantoruan, \& Tampubolon, 2019; Martawijaya \& Hasyim, 2019). Oleh karena itu, guru dan peserta didik menggali kembali nilai-nilai kearifan lokal yang ada agar tidak hilang ditelan perkembangan zaman.

Lemahnya pemahaman masyarakat terkait dengan nilai-nilai kearifan lokal sangat berdampak pada pola pikir, sikap, dan tindakan individu maupun kelompok (Amirin, 2013; Arif, 2017; Talan, 2018). Masyarakat jauh lebih peduli dan perhatian akan hal-hal yanag berkaitan dengan perkembangan jaman. Seiring dengan perkembangan zaman di era globalisasi, modernisasi banyak hal-hal yang berubah pada diri masyarakat. Minimnya pemahaman akan nilai-nilai kearifan lokal tersebut sangat berpotensi dalam menciptakan konflik sara dan ras (Anjani, 2020; Syahrul \& Djaha, 2020; Syahrul, 2020).

Faktanya, nilai-nilai kearifan lokal tidak dijaga dan dipelihara melalui pendidikan untuk generasi muda, maka hal ini akan hilang terdegradasi oleh arus globalisasi dan modernisasi (Un, 2020). Pada era globalisasi, dan modernisasi manusia sudah banyak yang memiliki sikap apatis dengan nilai-nilai kearifan lokal sebagai bagian dari multikultural bangsa dalam budaya (Syahrul, 2020; Syahrul et al., 2019). Dalam hal ini banyak ditemukan di asyarakat di mana satu sama lain sudah tidak saling menghargai perbedaan, keberagaman, dalam berbagai aspek seperti etnis, suku, budaya, dan agama (Nurbayani \& Sriat, 2018).

Sekolah sebagai lembaga edukasi memegang peranan penting dalam menanamkan nilai multikultular pada siswa sejak dini (Syahrul \& Djaha, 2020; Syahrul, 2019). Bila sejak dini mereka telah memiliki nilai-nilai kebersamaan, toleran, cinta damai, dan menghargai perbedaan, maka nilai-nilai tersbut akan tercermin pada tingkah-laku mereka sehari-hari karena terbentuk pada kepribadianya (Chalmers, 2019; Chase \& Morrison, 2018; Cherner \& Fegely, 2018). Bila hal tersebut berhasil di miliki oleh generasi muda kita sejak dini, maka 
kehidupan mendatang dapat diprediksi akan relatif damai dan penuh penghargaan antar sesama dapat terwujud (Jun, 2016; Kim \& So, 2018; Lawyer, 2018).

Pendidikan multikultular berbasisi kearifan lokal harus di ajarkan kepada peserta didik melaui pembelajaran secara keseluruan pada tiap mata pelajaran di sekolah (J. A. Banks, 2017; J. A. Banks \& Banks, 2010; James A. Banks, 2014). Di sisi lain, hal yang lebih tepat dilakukan dengan memasukan kearifan lokal dalam mata pelajaran di sekolah (Syahrul et al., 2019). Sehinga kurikulum dari Kementerian Pendidikan dan Kebudayaan tidak menjadi tumpuuan bagi guru yang mengajar di kelas, akan tetapi hurus dapat menyesuaikan dengan kebutuhan daerah masing-masing. Agar guru dapat mengajarkan nilai-nilai kearifan lokal dalam pendidikan multikultular sehinga memberikan pemahaman bagi peserta didik agar bias menerima dalam setiap perbedaan dari berbagai aspek (Syahrul \& Arifin, 2018).

Dalam meminimalisir hal di atas, guru di sekolah telah menanamkan nilainilai kebersamaan, toleran, dan mampu menyesuaikan diri dalam berbagai perbedaan. Proses pendidikan ke arah ini dapat ditempuh dengan pendidikan multikultural. Pendidikan multikultural merupakan proses penanaman cara hidup menghormati, tulus, dan toleran terhadap keragaman budaya yang hidup di tengah-tengah masyarakat plural (Altaş, 2015; Syahrul, 2020; Zilliacus, Holm, \& Sahlström, 2017). Dengan demikian, pendidikan multikultural mampu memberikan kelenturan mental peserta didik dalam menghadapi benturan konflik sosial.

Penelitian yang pernah dilakukan sebelumnya oleh Nurbayani \& Sriat (2018) tentang pendidikan multikultural berbasis kearifan lokal dalam pembentukkan karakter peserta didik di Tanjung Pinang Provinsi Kepualauan Riau. Mereka melihat bahwa pendidikan tidak dapat ditafsirkan terbatas sebagai implementasi ilmu pengetahuan saja, melainkan harus lebih luas, sehingga para peserta didik memiliki pemahaman terhadap kearifan lokal. Pendidikan multikultural berbasis kearifan lokal dapat digunakan untuk memecahkan berbagai masalah (Syahrul et al., 2019). Selain itu, tujuan pendidikan multikultural berbasis kearifan lokal adalah memberi pemahaman kepada peserta didik tentang nilai-nilai kearifan local (Husin, Wiyanto, \& Darsono, 2018; Sihabudin, 2013). Hal tersebut diharapkan dapat menumbuhkan semangat kebangsaan, patriotisme, hingga kebudayaan peserta didik, tanpa etnosntrisme. Di tingkat lokal, pendekatan pendidikan multikultural harus dilakukan secara kontekstual. Dengan demikian, peserta didik akan memiliki lebih banyak rasa hormat terhadap keberagaman dan berbagai 
aspek seperti agama, status sosial, gender, kemampuan, umur dan ras, dan lainlain (Jantzen, 2020; Lawyer, 2018).

Perbedaan penenelitiaan yang akan peneliti lakukan dengan penelitian sebelumnya dilakukan oleh Nurbayanui dan Sriat adalah penelitian sebelumnya menekankan pada pengenalan pendidikan multikultural pada peserta didik, sehinga peserta didik mampu memhamai perbedaan-perbedaan yang ada di bangsa ini. Oleh karena itu, penelitian yang dilakukan di sini adalah untuk mengetauhi kearifan lokal yang di SDN 98 Tongko dan bagaiman cara mereka saling menerima dan menghargai antar sesama peserta didik. Jika kearifan lokal tidak dijaga dan di pelihara bagi generasi muda maka multikultural justru akan menjadi masalah di bangsa ini.

Penelitian ini penting karena kemajemukan budaya merupakan ciri masyarakat Indonesia yang sering dibanggakan. Sebagaimana yang dikemukan oleh Soetapa kemajemukan itu juga dapat menjadi bencana bagi bangsa Indonesia, karena kemajemukan dapat menjadi sumber dan potensi konflik yang dapat mengganggu dan bahkan mengancam kesatuan dan persatuan bangsa, Banyak orang yang belum juga menyadari bahwa kemajemukan itu menyimpan potensi konflik yang dapat mengancam kehidupan berbangsa dan bernegara (Syahrul, 2020). Sangat penting menanamkan nilai-nilai multikultular sejak awal pada anggota masyarakat Indonesia. Berangkat dari berbagai masalah di atas maka peneliti melakukan penelitian dengan judul "Menumbuhkan Kearifan Lokal pada peserta Didik Melalui Pendidikan Multikultulral di SDN 98 Tongko". Adapun tujuan yang dicapai pada penelitian ini yakni untuk mengetahui pertumbuhan kearifan lokal pada peserta didik di SDN 98 Tongko dan untuk mengetahui faktorfaktor apa saja mempengaruhi perbedaan kearifan lokal berbasis multikultural di SDN 98 Tongko.

\section{Tinjauan Literatur}

\section{Kearifan Lokal Masyarakat Tongko}

Masyarakat Tongko terkususnya di Duri memiliki banyak suku yaitu dari Suku Bugis, Duri, dan Toraja. Dari sekian suku yang dipaparkan masing-masing memiliki banyak kearifaan lokal tersendiri entah itu dari kerajinan tangan, makanan kas, alat musik, tarian adat dan yang lebih spesifiknya adalah tutur adat. Mereka memiliki kerajianan tangan, yaitu pembuatan kain tenun dari khas masyarakat Toraja itu sendiri. Biasanya kerajianan tangan ini dikerjakan oleh masyrakat pedalaman karena telah menjadi bagian kearifan lokal (Syahrul et al., 2019). 
Sementara itu, makanan khas seperti siri pinang telah menjadi ciri Orang Toraja karena sudah menyatuh dengan kearifan lokal. Selain itu, alat musik tradisional yang paling populer dalam kebudayan masraykat Duri adalah Musik Bambu. Lebih lengkpnya lagi adalah tarian adat yang merupakan salah satu tarian kearifan lokal.

\section{Pendidikan Multikultular di Sekolah}

Pendidikan multikultural dikenal sebagai suatu teori yang relevan bagi masyarakat Tongko yang heterogen. Pendidikan multikultural yang dikembangkan di Indonesia sejalan pengembangan pendidikan yang dijalankan di Tongko. Wacana tidak hanya dapat dilaksanakan melalui pendidikan formal, tetapi juga dapat dimplementasikan dalam kehidupan masyarakat maupun dalam keluarga (pendidikan nonformal dan informal). Dalam pendidikan formal pendidikan multikultural ini tidak harus menjadi mata pelajaran sendiri namun dapat diintegrasikan dalam mata pelajaran lain yang mempunyai tujuan pendidikan yang sama. Pada tingkat sekolah usia dini dapat diintegrasikan dalam kurikulum pendidikan misalnya dalam permainan, dan pada tingkat SD, SLTP maupun Sekolah menengah, pendidikan multikultural ini dapat diintegrasikan dalam bahan ajar seperti PPKn, agama, sosiologi dan antropologi (Syahrul \& Djaha, 2020).

Pendidikan multikultural adalah kegiatan belajar mengajar yang memberikan pengetahuan, pemahaman, sikap dan tindakan dalam mengembangakan atas kondisi perbedaan dan persamaan peserta didik terkait dengan jenis kelamin, ras, budaya, etnik dan agama (Syahrul, 2019). Proses pembelajaran ini dapat mengembangkan kondisi yang kondusif yang memandang keunikan peserta didik tanpa membedakan karakteristik latar belakang budayanya (Ashmawi, Sanchez, \& Carmona, 2018; Chase \& Morrison, 2018).

Banks mengungkapkan empat tahap implementasi pendidikan multicultural, yaitu (1) membawa masuk ke sekolah elemen kultur masyarakat, seperti peringatan hari-hari besar, kebiasaan dan ritual kultural, makanan, pakaian, dan seni. (2) Menambah isi dan materi pembelajaran tanpa merubah struktur kurikulum-keilmuan. (3) Merubah struktur kurikulum keilmuan agar siswa dapat mengkaji materi dan kondisi masyarakat dari berbagai perspektif kultural. (4) Siswa membuat keputusan dan mengambil tindakan berkaitan dengan masalah personal, sosial kemasyarakatan (J. A. Banks, 2017). 


\section{Metode}

Lokasi penelitian ini di SDN 98 Tongko Kecamatan Baroko Kabupaten Enrekang. Penelitian berlangsung selama satu tahun. Subjek yang terdapat pada penelitian ini adalah siswa SDN 98 Tongko. Peneliti memilih beberepa siswa sebagai subjek penelitian ini karena kamajemukan suku merupakan ciri masyarakat Indonesia yang sering dibanggakan. Banyak orang yang belum juga menyadari bahwa kemajemukan itu menyimpan potensi konflik yang dapat mengancam kehidupan berbangsa dan bernegara. Oleh karena itu, sangat penting menanamkan nilai-nilai multikultular sejak awal pada anggota masyarakat Indonesia. Selain siswa, peneliti juga mewawancarai guru dan kepala sekolah. Teknik pengumpulan data yang dilakukan peneliti adalah wawancara yang dilakukan mengumpulkan data langsung dari kepala sekolah, guru dan siswa secara mendalam dan menyeluruh. Wawancara dilakukan dalam bentuk terencana untuk mendapatkan informasi agar wawancara fokus kepada objek penelitian, maka sebelumnya telah disusun struktur pokok permasalahan. Wawancara dilaksanakan pada saat jam istrahat karena pada jam istrahat kepala sekolah dan guru dapat diwawancarai tanpa mngganggu KBM di kelas, sedangkan siswa lebih banyak berkumpul, peneliti akan melihat keanekaragaman budaya, bahasa, agama, status sosial, gender dan ras yang ada di Tongko.

Peneliti menggunakan analisis data kualitatif dilakukan secara interaktif dan berlangsung secara terus menurus samapai tuntas, sehingga datanya jenuh. Ukuran kejenuhan data ditandai dengan tidak diperolehnya lagi data atau informasi baru. Dalam penelitian ini, analisis meliputi: (1) pengumpulan data yang diperoleh dari hasil wawancara di lapangan yang terdiri dari dua aspek yaitu deskripsi dan refleksi. (2) Reduksi data dilakukan selama penelitian berlangsung, setelah peneliti di lapangan, sampai laporan tersusun. Reduksi data merupakan bagian dari analisis data dengan suatu bentuk analisis yang mengarahkan data yang diperlukan dan membuang data yang tidak diperlukan. (3) Penyajian data dalam penelitian ini dilakukan dalam bentuk uraian singkat. Penyajian data juga didukung dengan kutipan wawancara dengan orang yang memberi informasi secara langsung sehingga data yang disajikan dapat dipertanggungjawabkan kebenaranya. (4) Penarikan kesimpulan dilakukan dengan cara melihat hasil pengamatan lapangan agar hasilnya sesuai. Keseluruhan sajian data ini kemudian dirumuskan dan diambil kesimpulan secara singkat (Creswell, 2013).

\section{Hasil \& Diskusi}




\section{Menumbuhkan Kearifan Lokal Melalui Pendidikan Multikultular di SDN 98 Tongko}

Nilai kearifan lokal dalam masyarakat di wilayah Buntu Limbong pada kususnya desa Parombean, berperan sebagai wadah komunikasi yang menghubungkan sekolah dalam menanamkan nilai-nilai kearifan lokal, sehingga dapat meminimalisasi potensi konflik di lingkungan sekolah SDN 98 Tongko. Salah satu wujud komunikasi tersebut adalah pihak sekolah membentuk wadah untuk kelompok siswa berinetraksi di luar kegiatan belajar mengajar seperti kegiatan ekstrakurikuler berbasis kearifan lokal berupa olahraga dan keseniaan untuk memberikan pengaruh positif sebagai bentuk kearifan lokal.

Kearifan lokal memiliki berbagai macam elemen dari suatu daerah. Di SDN 98 Tongko merupakan salah satu sekolah dasar yang ada di Kecamatan Baroko, khususnya muatan lokal dan kesenian, dari jenis sekolah maka dapat kita lihat bahwa di sekolah ini lebih mengutamakan mata pelajaran yang bersifat budaya dan tambahahannya adalah mata pelajaran umum lainnya, muatan lokal merupakan salah satu mata pelajaran yang memuat tentang kearifan lokal yang dipelajari di kelas dan diwujudkan dalam kehidupan sehari-hari terkhusus di lingkungan sekolah SDN 98 Tongko. Kearifan lokal yang ada di tengah keberagaman wajib ditumbukkan dan diwujudkan dengan kerja sama antara peserta didik, guru dan kepala sekolah sebagai penanggungjawab di sekolah tersebut kearifan lokal yang ditumbuhkan melalui kebiasaan baik dilingkungan sekolah seperti bersalaman, berdoa bersama, menjaga kebersihan dan lain sebagainya. Kearifan lokal yang dituangkan dalam berbagai seni dan olahraga wajib untuk diketahui maknanya agar dapat dilaksanakan dengan baik.

Hasil observasi yang peneliti lakukan dalam penelitian pada tanggal 1 Januari 2020 pukul 09:00 mengenai kearifan lokal di tengah keberagaman peserta didik di SDN 98 Tongko baik dalam proses KBM dan diluar KBM memiliki potensi penumbuhan kearfan lokal yang baik. Peserta didik di SDN 98 Tongko hidup di tengah kenbergaman yang multikultural, para peserta didik yang berasal dari berbagai daerah diasramakan disekitar lingkungan sekolah. Di SDN 98 Tongko memiliki berbagai macam latar belakang kebudaan yang berbeda-beda.

Hasil Wawancara yang dilakukan pada tanggal 12, 18, dan 25 Januari 2020 dengan informan yaitu kepala sekolah dan guru kelas. Wawancara ini dilakukan untuk mengetahui penerapapan dan penumbuhan kearifan lokal di SDN 98 Tongko dari aktivitas perserta didik dengan latar belakang agama, status sosial, 
gender, kemampuan, umur dan ras, yang beragam. Berdasarkan hasil wawancara dengan kepala sekolah, Sasmawati mengatakan bahwa,

kearifan lokal yang ada di dalam SDN 98 Tongko Kecamatan Baroko Kabupaten Enrekang ditumbuhkan melalui Pembelajaran formal ataupun nonformal dan pembiasan hidup bersama di daerah asrama sekolah. Kearifan lokal yang ada di dalam SDN 98 Tongko ditumbuhkan melalui pembelajaran formal dan nonformal, pembelajaran formal meliputi KBM setiap hari dari jam 07:30-13:00 sedangkan pembelajaran nonformal meliputi ekstrakurikuler berupa latihan olaraga, musik dan tarian dan pembiasaan hidup bersama di lingkungan sekolah.

Menumbuhkan kearifan lokal di SDN 98 Tongko melalui kegiatan belajar mengajar (KBM) guru dalam proses pembelajaran menekankan pada optimalisasi peran rasionalitas bagi siswa, praktek dan pembiasaan perbedaan pendapat. Cara kerja yang dipakai dalam proses pembelajaran dengan cara memberikan kesempatan munculnya ide atau gagasan dari siswa. Pemunculan gagasan atau ide dikemas dengan suasana yang menyenangkan atau tidak menakutkan.

Pendidik menggunakan startegi atau metode dalam pembelajaran, yaitu metode diskusi dan pembelajaran nonformal. Pendidik merangkul seluruh siswa dari setiap jurusan untuk melaksanakan latihan bersama yaitu ada siswa yang latihan olaraga dan adapula yang latihan tarian, karena di dalam Sekolah SDN 98 Tongko peserta didik berasal dari beragam budaya, etnis ras, agama sehingga pendidik menumbuhkan kearifan lokal melalui kegiatan formal dan nonformal.

Pembiasaan hidup bersama di asrama SDN 98 Tongko dapat kita ketauhi bahwa ada dua asrama yakni asrama putra dan putri, yang banyak menampung peserta didik berbagai daerah, di dalam asrama peserta didik biasa melakukan kegiatan-kegiatan bersama, makan bersama bahkan sampai berdiskusi bersama, anaka-anak melakukan kerja sama dalam pembersihan asrama. Dari sekian banyak kegiatan-kegiatan asrama tersebut bisa mempererat tali persaudran walaupun peserta didik berasal daerah yang berbeda. Berdasrkan hasil wawancara dengan guru kelas VI bahwa,

pentingnya kearifan lokal dalam pembelajaran di kelas, membiasakan bersalaman, mengunakan bahasa Indonesia dalam pembelajaran dan komunikasi dalam aktivitas sekolah agar peserta didik menghargai kearifan lokal dari setiap daerah masing-masing di tengah keberagaman (Johar Perlinda, 18/03/2020).

Penggunaan bahasa Indonesia merupakan bahasa pemersatu di SDN 98 Tongko hampir semua peserta didik dari dusun yang berbeda-beda. Maka dari itu untuk bisa menyatukan para peserta didik dengan mengunakan bahasa Indonesia dan tidak menggunakan bahasa daerah masing-masing agar tidak ada pembeda di 
antara mereka. Pendidik juga mengajarkan kepada peserta didik bagaimana tata krama dan sopan santun kepada setiap guru dan setiap peserta didik agar guru dan peserta didik saling menghormati satu sama lain yang ada di dalam SDN 98 Tongko.

Berdasarkan penjelasan di atas senada dengan pendapat yang dikemukakan oleh Shannon-Baker (2018) menyatakan bahwa selain memiliki fungsi sebagai sarana utama untuk berkomunikasi bahasa juga berfungsi sebagai alat intergrasi dan adaptasi sosial, maksudnya melalui bahasa seseorang dapat perlahan-lahan belajar mengenal adat istiadat, tingkah laku, tatakrama dan mampu beradaptasi dengan segala hal. Berdasarakan hasil wawancara dengan guru kelas IV pak Sinusi, bahwa "kearifan lokal dapat diterapkan dan ditumbuhkembangkan di sekolah dimulai, dari pembagian kelompok dalam diskusi pada saat proses pembelajaran saat KBM dan ibadah non formal lingkungan sekolah setiap harinya" (Sinusi, 25/03/2020).

Kearifan lokal ditumbuhkembangkan oleh pendidik mulai dari pembagian kelompok diskusi pada saat pelajaran karena didalam rungan kelas peserta didiknya beragam mulai dari budaya, etnis, ras dan agama, dengan diskusi peserta didik dapat berkolaborasi dan menjalin hubungan harmonis saat belajar. Sikap persahabatan dapat ditunjukan saat diskusi di kelas, sehingga dengan kerja sama tolong menolong pada saat pemecahan masalah diskusi peserta didik mudah menemukan solusinya, bukan hanya diskusi kelompok saat proses blajar mengajar tetapi juga ibadah non formal di dalam asrama juga di lakukan setiap hari tanpa memandang perbedaan keyakinan bagi peserta didik.

\section{Fakor-faktor yang Mempengaruhi Perbedaan Kearifan Lokal di SDN 98 Tongko}

Faktor-faktor yang mempengaruhi perbedaan kearifan lokal di SDN 98 Tongko, yaitu, mata pelajaran muatan lokal yang memuat materi kearifan lokal berbasis multikultural hanya merupakan mata pelajaran tambahan dari mata pelajaran umum sehingga tidak diprioritaskan, kearifan lokal berbasis multikultural ditumbuhkembangkan dalam praktek kejuruan, dan membutuhkan kesungguhan yang lebih daripada penerapan di sekolah pada umumnya karena melibatkan fisik, dan keberagaman yang ada lebih cepat memicu pertengkaran fisik. Peneliti melihat bahwa kesulitan penerapan kearifan lokal pada pserta didik di SDN 98 Tongko dari pada sekolah Dasar pada umumnya.

Hasil observasi yang dilakukan dari berkumpulnya peserta didik pada jam istirahat dan sepulang sekolah saat di lingkungan masyarakat menunjukan bahwa 
masih adanya sukuisme yang tinggi sehingga kearifan lokal sulit untuk ditumbuhkan, etnis yang berbeda (asal tempat tinggal dari desa dan dusun), dan komunikasi antar peserta didik, peserta didik dan guru, guru dan guru merupakan faktor yang mempengaruhi kearifan lokal yang bersifat multikltural.

Hasil wawancara menganai faktor-faktor yang memepengaruhi kearifan lokal berbasis multikultular di SDN 98 Tongko menurut pandangan kepala sekolah dan guru-guru mata pelajaran tersebut menunjukkan bahwa,

faktor yang mempengaruhi kearifan lokal di SDN 98 Tongko ini sendiri adalah dilihat dari sekolahnya dimana sekolah ini menerapkan kearifan lokal berbasis multikultular lebih menekankan pada penerapan kearifan lokal ini yang di kolaborasikan dengan setiap kejuruan yang ada di SDN 98 Tongko yang melibatkan peserta didik berbagai daerah (Sasmawati , 12/032020).

Faktor yang mempengaruhi kearifan lokal disekolah SDN 98 Tongko dilihat dari kamajemukan suku, ras dan agama. Oleh sebab itu, pendidik harus mengkolaborasikan setiap kejuruan yang ada di dalam sekolah SDN 98 Tongko tersubut karena di setiap kejuruan peserta didik berasal dari suku, ras dan agama yang berbeda-beda. Berdasarkan hasil wawancara dengan Ibu Hasna bahwa,

perbedaan faktor yang mempengaruhi nilai keraifan lokal yang ada di siswa SDN 98 Tongko adalah keberadaan berbagai agama, status sosial, gender, kemampuan, umur dan ras, sehingga pendidikan multikultular diterapkan saat praktek kegiatan ekstrakulikuler (Hasna, 18/03/2020).

Sekolah SDN 98 Tongko adalah sekolah keberbakatan olahraga, di mana peserta didik berasal dari berbagai etnis, untuk menyatukan peserta didik dari berbagai etnis maka lembaga sekolah mengadakan kegiatan ekstrakulikuler di dalam sekolah tersebut, adapun kegiatan ekstrakulikuler berupa oalahraga dan tarian, setiap peserta didik wajib mengikuti satu kegiatan ekstrakulikuler sesuai dengan bakat atau kemampuan yang dimiliki oleh peserta didik. Berdasarkan hasil wawancara dengan Ibu Johar Perlinda.

perbedaan kearifan lokal berbasis multikultular di SDN 98 Tongko di mana kearifan lokal ini memiliki beberapa faktor dalam penerapan seperti jangka waktu pengkolaborasian olahraga dan seni, kearifan lokal untuk acara tertentu dan latihan, kombinasi kearifan lokal dengan berbagai olahraga dan seni untuk persiapan ajang atau perlombaan (Johar Perlinda, 25/03/2020).

Sekolah SDN 98 Tongko adalah sekolah yang berprestasi di kecamatan Baroko, wadah ini biasanya menyiapkan peserta didiknya untuk mengikuti perlombaan yang ada di Kecamatan Baroko, pendidik kesulitan untuk melatih peserta didiknya karena peserta didiknya berasal dari berbagai etnis, sehingga pendidik membutuhkan jangka waktu untuk mengkolaborasikan olahraga dan seni. 
Berdasarkan hasil observasi dan wawancara diatas maka peneliti melihat bahwa menanamkan nilai kearifan lokal dan faktor yang mempengaruhi perbedaan kearifan lokal berbasis multikultular di SDN 98 Tongko yaitu dari objek (sekolah) dan subjek (siswa, guru dan kepala sekolah). menyatakan faktor-faktor kearifan lokal adalah kerukunan beragamaan dalam wujud praktik sosial yang dilandasi suatu kearifan dari budaya. Faktor-faktor kearifan lokal dalam masyarakat dapat berupa budaya (nilai, norma, etika, kepercayaan, adat istiadat, hukum, dan aturan-aturan khusus). Nilai-nilai luhur terkait kearifan lokal meliputi cinta kepada Tuhan, alam, beserta isinya, tanggungjawab, disiplin, dan mandiri, jujur, hormat dan santun.

\section{Kesimpulan}

Berdasarkan pembahasan di atas, kearifan lokal di SDN 98 Tongko mengenai penumbuhkan nilai-nilai kearifan lokal pada peserta didik dan faktor-faktor yang mempengaruhi kearifan lokal di SDN 98 Tongko, dapat disimpulkan bahwa, kearifan lokal di lingkungan sekolah merupakan hasil dari kerjasama antara peserta didik, guru dan kepala sekolah. Agar nilai-nilai kearifan lokal dapat ditumbuhkan dalam diri peserta didik, proses penumbuhan kearifan lokal ini dilakukan melalui kegiatan formal dan nonformal di lingkungan sekolah dan di lingkungan sekolah. Dalam kegiatan formal penumbuhan kearifan lokal yakni pada proses belajar mengajar. Sedangkan dalam kegiatan non formal yakni berupa pembiasaan hidup bersama pada kegiatan tarian, olahraga, dan musik. Upaya menumbuhkan nilai-nilai kearifan lokal pada peserta didik di SDN 98 Tongko dipengaruhi oleh beberapa faktor. Fakor-faktor tersebut adalah keberagaman peserta didik dalam hal etnis, budaya,status sosial dan agama serta keterampilan guru dalam pengkolaborasian peserta didik untuk mengikuti ajang perlombaan olahraga dan seni.

\section{Referensi}

Altaş, N. (2015). Towards Comprehensive Religious Education (a Trial for New Research Ways within the Frame of Liberalism and Multiculturalism Concepts). Procedia - Social and Behavioral Sciences, 174, 131-136. https://doi.org/10.1016/j.sbspro.2015.01.637

Amirin, T. M. (2013). Implementasi Pendekatan Pendidikan Multikultural Kontekstual Berbasis Kearifan Lokal di Indonesia. Jurnal Pembangunan Pendidikan: Fondasi dan Aplikasi, 1(1). https://doi.org/10.21831/jppfa.v1i1.1047

Anjani, F. (2020). Teori Pembelajaran Konstruktivistik dalam Meningkatkan Hasil Belajar Sosiologi di SMA. Sociological Education, 1(1), 34-41. https://doi.org/10.12345/socioedu.v1i1.233 
Arif, M. (2017). Deradikalisasi Islam Melalui Pendidikan Multikultural Berbasis Kearifan Lokal pada Masyarakat Cigugur. AKADEMIKA: Jurnal Pemikiran Islam, 22(1), 51-76. (International). https://doi.org/10.32332/akademika.v22i1.716

Ashmawi, Y. P. E., Sanchez, M. E. H., \& Carmona, J. F. (2018). Testimonialista Pedagogues: Testimonio Pedagogy in Critical Multicultural Education. International Journal of Multicultural Education, 20(1), 67-85. https://doi.org/10.18251/ijme.v20i1.1524

Banks, J. A. (2017). An Introduction to Multicultural Education. Boston: Pearson Education. Retrieved from https://www.pearsonhighered.com/assets/preface/0/1/3/4/0134800362.pdf

Banks, J. A., \& Banks, C. A. M. G. (2010). Multicultural Education: Issues and Perspectives. Wiley. Retrieved from https://books.google.co.id/books?id=e1ITbOA2jhQC

Banks, James A. (2014). Diversity, Group Identity, and Citizenship Education in a Global Age. Journal of Education, 194(3), 1-12. https://doi.org/10.1177/002205741419400302

Chalmers, F. G. (2019). Celebrating Pluralism Six Years Later: Visual Transculture/s, Education, and Critical Multiculturalism. Art, Culture, and Pedagogy, 57-70. https://doi.org/10.1163/9789004390096_007

Chase, S. L., \& Morrison, K. (2018). Implementation of Multicultural Education in Unschooling and its Potential. International Journal of Multicultural Education, 20(3), 39-58. (school-age children, homeschooled children, Growing Without Schooling magazine). https://doi.org/10.18251/ijme.v20i3.1632

Cherner, T., \& Fegely, A. (2018). Answering Damarin's Call: How iOS Apps Approach Diversity, Equity, and Multiculturalism. International Journal of Multicultural Education, 20(1), 21-47. (iOS apps). https://doi.org/10.18251/ijme.v20i1.1464

Creswell, J. W. (2013). Qualitative Inquiryand Researc Design. New Delhi: SAGE Publication. Retrieved from https://books.google.co.id/books?id=Ykruxor10cYC\&printsec=frontcover\#v=onepage \&q\&f= false.

Husin, V. E., Wiyanto, W., \& Darsono, T. (2018). Integrasi Kearifan Lokal Rumah Umekbubu dalam Bahan Ajar Materi Suhu dan Kalor untuk Meningkatkan Motivasi dan Hasil Belajar Siswa SMA. Physics Communication, 2(1), 26-35. https://doi.org/10.15294/physcomm.v2i1.11491

Jantzen, C. A. (2020). Two perspectives on togetherness: Implications for multicultural education. Multicultural Education Review, 31-37. https://doi.org/10.1080/2005615X.2020.1720136

Jun, E. J. (2016). Rethinking Multicultural Education: Teaching for Racial and Cultural Justice. Multicultural Perspectives, 18(3), 179-181. https://doi.org/10.1080/15210960.2016.1191294

Kennedy, P. S., Tobing, S. J., Lumbantoruan, R., \& Tampubolon, E. (2019). Diskusi Tentang Peran Kearifan Lokal dalam Pemanfaatan Sumber Daya Laut dengan Kelompok Masyarakat Maluku Barat Daya. JPM (Jurnal Pemberdayaan Masyarakat), 4(1), 355-346. https://doi.org/10.21067/jpm.v4i1.3063

Kim, J.-H., \& So, K. (2018). Understanding the "Other": Rethinking Multiculturalism in South Korea through Gadamer's Philosophical Hermeneutics. International Journal of Multicultural Education, 20(1), 102-117. https://doi.org/10.18251/ijme.v20i1.1509 
Lawyer, G. (2018). The Dangers of Separating Social Justice from Multicultural Education: Applications in Higher Education. International Journal of Multicultural Education, 20(1), 86-101. https://doi.org/10.18251/ijme.v20i1.1538

Martawijaya, M. A., \& Hasyim, M. (2019). Pengembangan Buku Fisika peserta didik berbasis kearifan lokal untuk meningkatkan literasi sains peserta didik Sekolah Menengah Atas. Seminar Nasional LP2M UNM, l(1). Retrieved from http://ojs.unm.ac.id/semnaslemlit/article/view/8158

Nurbayani, S., \& Sriat, L. (2018). Pendidikan Multikultural Berbasis Kearifan Lokal Dalam Pembentukkan Karakter Peserta Didik Di Tanjungpinang-Keprian. 27(2), 150-155. https://doi.org/10.17509/jpis.v27i2.11185

Shannon-Baker, P. (2018). A Multicultural Education Praxis: Integrating Past and Present, Living Theories, and Practice. International Journal of Multicultural Education, 20(1), 48-66. (N/A). https://doi.org/10.18251/ijme.v20i1.1518

Sihabudin, A. (2013). Literasi Media dengan Memberdayakan Kearifan Lokal. Communication, 4(2). https://doi.org/10.36080/comm.v4i2.55

Syahrul, \& Djaha, S. S. M. (2020, October 15). Pluralism Consciousness for Students at Muhammadiyah University of Kupang Through Multicultural Education. 166-173. Atlantis Press. https://doi.org/10.2991/assehr.k.201015.026

Syahrul, S. (2019). Internalisasi Pendidikan Multikultural dan Inklusif pada Anak Pengungsi Internasional di Kota Makassar. JPK (Jurnal Pancasila dan Kewarganegaraan), 4(3), 25-34. https://doi.org/10.24269/jpk.v4.n3.2019.pp25-34

Syahrul, S. (2020). Menanamkan Kemuhammadiyaan Pada Mahasiswa Non-Muslim Melalui Pendidikan Multikultural di Universitas Muhammadiyah Kupang. EDUKASI: Jurnal Penelitian Pendidikan Agama Dan Keagamaan, 18(2). https://doi.org/10.32729/edukasi.v18i2.643

Syahrul, S., \& Arifin, A. (2018). Kebijakan Pendidikan Multikultural pada Peserta Didik Non-Islam di Sekolah Muhammadiyah Kota Kupang. JPK (Jurnal Pancasila Dan Kewarganegaraan), 3(2), 1-9. https://doi.org/10.24269/jpk.v3.n2.2018.pp1-9

Syahrul, S., Arifin, A., Datuk, A., Almu, F. F., \& Ramlah, S. (2019). Pengembangan Bahan Ajar Berorientasi Literasi Kearifan Lokal di Mas Al-Hikmah Soe Nusa Tenggara Timur. JPM (Jurnal Pemberdayaan Masyarakat), 4(2), 371-379. https://doi.org/10.21067/jpm.v4i2.3628

Talan, M. R. (2018). Pengembangan Buku Suplemen Teks Negosiasi Bermuatan Kearifan Lokal Timor dengan Pendekatan Content Language Integrative Learning. JP (Jurnal Pendidikan): Teori dan Praktik, 3(1), 24-33. https://doi.org/10.26740/jp.v3n1.p24-33

Un, O. (2020). Dampak Globalisasi Terhadap Gaya Hidup Peserta Didik di SMA Negeri 2 Kota Kupang. Sociological Education, 1(1), 27-33. https://doi.org/10.12345/socioedu.v1i1.231

Zilliacus, H., Holm, G., \& Sahlström, F. (2017). Taking steps towards institutionalising multicultural education - The national curriculum of Finland. Multicultural Education Review, 9(4), 231248. https://doi.org/10.1080/2005615X.2017.1383810 